\title{
Peirce's Creative Hallucinations in the Ontogeny of Abductive Reasoning
}

\author{
Donna E. West
}

\begin{abstract}
This inquiry proposes that Peirce's ultimate concept of dreams, which can be sub-divided in seven different functions, supply the raw material for habit-change inherent in every plausible inference. With references to developmental literature, I propose that dreams represent an outlet whereby children rely upon vivid directional icons of events (virtual habits) in reconciling logical anomalies provoked by unexpected happenings. Accordingly, dreams supply insights into how potential happenings materialize identifying which factors can enhance/enrich the effectiveness of potential event outcomes. Dreams of this creative kind are not obsessional or socially driven but rather form the bedrock for conceiving of many meritorious insights, as shown in phenomena like children's prelinguistic habits, word substitutions, overextensions, role-play and perspective taking.
\end{abstract}

Keywords: Peirce, dreams, virtual habits, deictic skills, children

\section{Introduction}

While some attention has been accorded to logical precursors necessary for abductive reasoning in children (West, 2014, 2016, in press), and in adults (Hintikka, 1998; Paavola, 2005; Kilpinen, 2016), none have tackled the affirmative effects of dreams (expressed in creative hallucinations) on inferential thought. This inquiry proposes that dreams, packaged in creative hallucinations, supply the raw material for habit-change inherent in every plausible inference; they represent an outlet whereby children rely upon vivid directional icons of events in reconciling logical anomalies provoked by unexpected happenings. This process illustrates how definite icons (Peirce, 1898, MS 843) excite the ingenuity necessary to determine regularities (however latent) which underlie practical abductions, or manipulative abductions, as Magnani (2001, p.55; 2009, p. 233) terms them.

According to Peirce (1903: EP 2, p.192), the kind of hallucinations (dreams) which possess the power to suggest meritorious inferences are not of the obsessional or social type; instead, they have some objective reality (especially in view of their deictic character), despite the fact that they can materialize from internal instinctual guesses. Because these dreams are rather specific and hence definite, they can compel the enactment of sound inferences in subsequent eventualities. They do not violate invariant principles; nor do they lead abducers "astray" (Gibson, 1979, p. 261), but give rise to "fictional objects," which Gibson claims to be essential to logic based advances. This inquiry initially provides the reader with the Peircean framework for how particular kinds of dreams qualify as catalysts for abduction. ${ }^{1}$ In later sections, evidence for how dreams foster abductive reasoning in ontogeny is the focus.

\footnotetext{
${ }^{1}$ See also Colapietro's (1988) and West's (2016d) discussion of dreams in a Peircean framework.
} 
D. West

\section{Characteristics of dreams}

Peirce proposes seven functions for dreams; they will be here organized chronologically according to when Peirce documented them. Implicit in Peirce's analysis of dreams and creative hallucination is a bifurcation between the bidden and the unbidden; the degree to which each fosters creative dreams and their applications is likewise addressed. Those which are unbidden, creative hallucinations may be more operational with a less significant knowledge base from which inferences are drawn. Some of these functions will be treated more explicitly than are others, given their relevance and place in ontogeny. These functions include:

(1) Dream maturation

(2) Isomorphism between iconic sign and object

(3) Icons of a general event template

(4) Daydreams of inward potential habits

(5) Novel event relations/verbs

(6) Percepts and fancies dependent upon habits

(7) Actions engendered by self-hypnotized imperatives, or self-controlled imaginatory hallucinations

There seem to be two basic kinds of dreams which highlight the utility of each of the seven functions, mainly, those which surface unbidden (i.e., not as a consequence of deliberation): functions 1, 4 and 6; and those dependent on perceptual real-world input but which go beyond perceptual input to logically-based inferencing: functions 2, 3, 5 and 7.

In 1877, Peirce illustrates the influence of dreams in experimental genres by demonstrating that Lavoisier's method to arrive at novel scientific conclusions "was not to read or pray, but to dream...that with some modification it [the dream] would have another result,...to end by publishing the last dream as a fact" (5.363). Indeed, Peirce indicates that it is ordinarily not the first dream which reveals viable rationale for previously unexplained events; rather, the key is a more mature dream - an ultimate form suggesting a serviceable explanation for a surprising consequence. Peirce is clear that what produces the mature dream (tantamount to an abduction) is forward-thinking/prospective imaginings, such that envisioning novel results in the experiment serves as the catalyst for dreams, which provide insights into logical relations between events. In short, a dream worthy of being the "last dream" published "as a fact" qualifies as an abduction - offering reasonable rationale for unexplained consequences. The dreams are "publish[ed]" as facts by virtue of Peirce's guessing instinct. These guesses do not begin as immature/less precise forms, but arise suddenly in a flash from spontaneous unbidden/unexpected hunches, e.g., the echo of a novel sound projecting from a decentralized amplification system.

Peirce's notion of daydreams (function 4), likewise underscores the unforeseen but potential effect of unbidden images - constituting not merely a forum for practice, but a playing field to generate and implement flashes of insight and novel courses of conduct as habits. ${ }^{2}$ Peirce indicates here that novel courses of conduct emanate from flashes of

\footnotetext{
2 “...day-dreams are often spoken of as mere-idleness; and so they would be but for the remarkable fact that they go to form habits, by virtue of which when a similar real conjecture arises we really behave in the manner we had dreamed of doing" (1893: 6.286).
} 
prefabricated action schemes outside of experience whose kind resurface unbidden. As such, their comparative degree of maturity is unclear, given their inception in a state between sleep and wakefulness. The substance of these prefabricated action images consists in insights derived from mental wanderings, which after surfacing in the inner world foreshadow courses of action in the outer world. This process illustrates the far-reaching influence of daydreams on elements of habit-change: habits begin as specific moving pictures in the mind and afterward materialize as alterations of belief and action in the outer world. It is obvious then that these courses of action changes are ultimately motivated by instinctual guessing often arrived at through insightful daydreams. Peirce determines that putting together events in novel ways constitutes the inception of inferential reasoning: "It is true that the different elements of the hypothesis were in our minds before; but it is the idea of putting together what we had never before dreamed of putting together which flashes the new suggestion before our contemplation" (1903: 5.181). It is the spontaneous emergence of daydreams which often underlies consolidations of event relations into novel foresights. The mental depiction ushers in new mantras of belief and behavior, which we never would have "put together" by deliberate and concerted effort. In short, daydreams uncover new affiliations across happenings; and the affordances which appreciate forge inferences that reveal further logical event relations.

Peirce's seventh dream function highlights the effect of perceptual experience in the inference-making process. In fact, the function of percepts is to access some empirical foundation for unbidden daydreams; hence Peirce's seventh dream function serves as a transition from dreams which surface unbidden to those which draw upon implicit knowledge of the real world. According to Peirce, percepts and fancies must logically homogenize with already accepted values and ontological principles derived from learned knowledge/beliefs and action patterns. In other words, what governs the integration of the world of experience with that of interpretation is both the individual's predilections (their innate dispositions) and acquired patterns of belief and conduct. The integration of these two sources marks the transition to more deliberative and conscious inferential thought. Peirce indicates that although these two knowledge bases from which dreams flow are initially distinct, they become homogenized as a direct consequence of reconciling percepts with daydreams/fancies and of proposing new habits:

Every sane person lives in a double world, the outer and the inner world, the world of percepts and the world of fancies. ... a man can be durably affected by his percepts and by his fancies. The way in which they affect him will be apt to depend upon his inborn disposition and upon his habits. (1907: 5.487)

Peirce is clear that habit is ascertained through integrating percepts with fancies/daydreams, and that habit is the agent for how fancies/percepts are interpreted, even as far as whether they have worth/validity to enhance the knowledge system at large.

In Peirce's more developed semiotic, he recognizes a more constructive character of "bidden" dreams - those which are both attentional and intentional (encompassing functions $2,3,5$ and 7). The attentional component surfaces from deliberative awareness of objects and their attributes as percepts, and the development of concepts/general characteristics from the percepts. The intentional component arises out of this latter seeking for habits/patterns in the real world. As such, what draws attention to object similarities and differentiations foundational to seeing relations which are not tangible, is Peirce's indexical sign. 
In 1885, when Peirce begins realizing the significance of index and its link with icons, eventually forming the Dicisign (in 1903), he recognizes the value of momentary, constructed images between signs (particularly icons) and their objects (consonant with dream function 2). This immeasurably informs his semiotic, since at this juncture even momentary, intermediate percepts (as dreams) contain merit as potential abductions. Peirce attributes the lack of isomorphism between sign and object to the disconnect between the "real" and dreams (mental images). This allowance for less exactitude encourages interpreters to operate upon representational form, rather than merely promoting a disposition/suddenly emerging hunch. The disconnect demonstrates that even iconic signs (dream functions 2 and 3) constitute altered replicas/inexact copies conceived of through mental constructions, such that percepts/perceptual judgments govern similarity relations: “...the distinction of the real and the copy disappears; and it [the individual existence of the sign] is for the moment a pure dream... at that moment we are contemplating an icon" (1885: 3.362). Accordingly, icons do not constitute exact replicas of objects, but are signs (dreams) bearing alterations imposed by the interpreting mind; hence they involve implicit judgments: comparisons with components of already established mental schemes, which derive from constructive processes, not predispositional ones. Subjective processes (consequent to attention to percepts) mediate primary representational features inherent to icons, despite the likeness between sign and object; consequently even a sign based upon resemblance with its object is partially a product of interpreters' idiosyncratic and self-determined mental assimilations/accommodations. This reliance upon pre-existing knowledge schemes within the inner world obviates that these iconic dreams are constructed by the mind following attention to percepts. This second function of dreams as icons of objects makes prominent the relevance of Peirce's categories to sign interpretation, in that dependence upon possibilities of altered replicas increases the need for Firstness-based operations. In this way, not only do icons qualify as dreams, because they supersede pure sensations, but also because the primacy of making perceptual judgments is obviated even when fashioning the most basic (motivated) sign types.

Nonetheless, in the third dream function the icon does not merely qualify as a picture of a scene in which an event is static; rather, it depicts dynamic event relations - moving event templates having episodic character. As such the deictic character of events culminates in shifting frames of reference, in which actors, receivers and benefactors play shifting roles. Peirce describes this template (dream functions 3 and 5), i.e., one that supports a dynamic iconic relation, as a "verb," given its means to both express a general valence relationship intrinsic to the state/action, and, at the same time, identify a specific application of that template in actual existence.

\footnotetext{
A verb is by its significance a mere dream, an imagination unattached to any particular occasion. It calls up in the mind an icon. A (relative) is just that, an icon, or an image without attachments to experience, without a local habitation and a name but with indications of the need of such attachments. (1887: 3.459)
}

Peirce makes plain that the verb template constitutes a model for an event type, characterizing the players/roles that need to or that can issue from that verb in a particular use - be they agents/receivers/patients of actions, or be they experiencers of states of affairs. Some of these relations are required upon selection of particular verbs (event templates), while only possibilities are created upon verb selection, e.g., write ordinarily requiring an animate agent and an inanimate object, whereas encourage compels both an animate agent and receiver/object. Both of these selections allow/compel deictic relations in the form of 
locative possibilities of the where, when, how, as well as agency. The semantic relations present in verb dreams (functions 3 and 5) obviates the importance of pragmatic relations, i.e., how events, as represented by verbs, compel animate/inanimate agents/receivers, or how the telicity/dynamicity of stative events determine the nature of the experiencer's involvement.

By 1887, Peirce began incorporating these deictic verb dreams into his semiotic such that, icons supersede single static events to suggest potential context changes. This sets the stage for developing his dual sign (icon and index) expressed in the Dicisign (1903: 2.312). The dual sign consists in an active, moving icon, demonstrating the sign's power to represent propositions (1904 EP 2, p.307) - thus showing direction and effect of the sign through the medium of an operationalized icon. This "living verb" constitutes a definite impetus for the interpreter to become the conduit for insights housed in verb-based dreams. Interpretants of these pictorial event templates likewise can imply assertions/arguments - not merely propositions (Bellucci, 2014, p. 539-540; West, in press). Furthermore, their meanings supersede energetic interpretants, rising to the level of logical ones. In short, the characterization of the icon as a verb (dream functions 3 and 5) ensures the introduction of viable inferences into hypothesis-making, increasing the likelihood for the emergence of constructive image processes into abductive processes. The upshot is that the influence of index in generating sound hypotheses is recognized, affording the elevation of index to an "informational" one (1903: MS 478, p.46-47). In turn, the index's informational character highlights key relations between depictions or features within depictions, directing attention to potential participant roles and event outcomes.

In 1893, Peirce applies his notion of habit to these relational dream functions ( 3 and 5). Such application illustrates how constructive dreams create novel images of event structures. In fact, newly constructed verb structures only approximate, but do not qualify as habit because they are but implicit conjectures of potential events. He refers to these habits as "virtual habits," in that, although they have not yet been actualized, they nonetheless qualify as likely modes of operation: "... we must acknowledge that there are inward actions - what might be called potential actions, that is actions which do not take place, but which somehow influence the formation of habits" (1893: 6.286). These episodic dreams, in essence, are tantamount to verbs, in that they prefigure action habits. They represent latent influences for actual behaviors, which ultimately constitute habit, in that they will materialize. Without these inward, constructed dreams (virtual habits), actual habits may never come to fruition (West, 2016c, in press).

Peirce's seventh dream function (self-control in imperative-based action, or selfcontrolled imaginatory hallucinations) supplies the ultimate step toward producing the behavior change from the abduction from the virtual habit, achieving consonance between the inner and the outer worlds. On the other, the pre-established knowledge bank is the compulsion to work out plausible courses of thought and action for self and/or for others and as such dream function seven incorporates self-control (MS 637: 12). This directive is especially poignant in Peirce's 1911 description of how, within the first five years of life, children utilize the categories to introduce and ultimately to reject or incorporate the virtual habit (verb dreams) into a general state of knowledge ["learning to govern himself so as to attain the ends that will prove satisfactory" (MS 674, p.9)]. The process entails either a resolution or a determination (far preferable) to believe or to act in a certain way when similar conditions arise (1907: 5.480, c1911: MS 674: 14-15). 
Peirce (MS 674, pp.11-14) painstakingly illustrates how children can target their compulsions and feelings to implement sound hypotheses. He demonstrates how imperatives to believe or act in recommended ways (abductions) transition from resolutions to determinations, "a settlement of his will" (MS 674, pp.14-15), when goal directed actions harness feelings. Peirce obviates the fact that the categories of Firstness and Secondness hasten the formation of new habits in Thirdness: "inner exertions of power" that can be directed by "an act of giving a compulsive command to one's self. Some books call it selfhypnotization." (1911: MS 674, pp.11-12). This "self-hypnotization" produces the belief and action directive to orchestrate self-controlled imperatives. Ascribing feelings to actions or action to feelings supplies a channeled will to convert undirected to directed affect, especially when the observer prescinds - fashioning on a single issue in the mind (see Section 5 for more discussion). At the same time, this process of toggling between prescinding and compulsions toward action with the impetus to comply with the imperative. This impetus to act is paramount for Peirce, because a "resolution" (without purpose) does not qualify as either a habit or a virtual habit, because it fails to possess the "force" to direct the action plan of the organism. But, without habit, soon to be implemented actions, inferences lack the raw material to qualify as abductions. Peirce implies that resolutions lack the force to become determinations because of their absence of clarity - they fail to be managed by a plan. But self-controlled imperatives ensure the conversion of virtual habits to action habits.

In fact, the imperative promotes an image of self in the proposed action scheme, thereby supplying clarity as determinations by the vividness of the image, the seventh dream function:

The effectiveness of the virtual habit relatively to that of a real habit is, I say, unquestionably than in proportion to the vividness of the imaginations that induce the former relatively to the vividness of the perception ... therefore, I venture to think, be a sort of self-hypnotizing effect, when we strain, in some obscure way, to influence our future behaviour by calling up as vividly as we can the image of a given sort of stimulus and that of our responding to it in the desired way. For we seem to command our organism or our soul as if we said to it: 'You will act thus: do you hear? Thus! Thus!! Thus!!!'(1909: MS 620, pp.24-25)

Here, Peirce makes explicit the purpose for imperatives (their self-action images) - to translate dreams into propositions and assertions through enactment, bringing organization and clarity to the thought by acting it out. This acting out constitutes pre-linguistic habits from virtual habits/dreams, in that language is not directing the underlying inferences.

In 1903, Peirce augments his dream model to account for the kind of dream which most hastens viable inferences, creative hallucinations: "Hallucinations were so very common, while hallucinations consequent with truth beyond the ken of sense were so very rare" (1903: 7.603). Only hallucinations derivative from sources other than direct experience of observables can ever suffice to "flash a suggestion before our contemplation," such that novel envisagements propel (superseding iconic similarity to percepts) plausible inferences which are responsible for habit change. Peirce's creative hallucinations represent the ultimate form of abductions because if they incorporate both unbidden and constructive dream functions-permitting daydreams and fancies to inform relational verb dreams, and the reverse. Peirce provides further details regarding the precise kind of hallucinations which propel this innovative inferencing when characterizing three types/grades of hallucination: "Hallucinations proper, obsessional hallucinations, will not down at one's bidding...there are also social hallucinations" (1903: EP2, p.192). 
The third and most productive type Peirce describes earlier in the same passage. He demonstrates how an unnamed painter exercised the creative kind of hallucination when recounting how the painter changed his action and beliefs consequent to a pictorial insight. This depiction of the inner world of the painter (mental image of the change in color of the backdrop curtain), provides the scaffold for the ultimate painting. Peirce recounts how the painter explains that the different color (of the curtain) "suited the picture better." Peirce follows by revealing his limited means to experience these forms of hallucination: "I myself am so utterly destitute of such hallucinatory imagination that I was astonished" (1903: EP2, p.192).

Peirce's "hallucinatory imagination" incorporates habit-change, in that his mental depiction (virtual habit) of the revised painting with the new backdrop illustrates not merely a change in action to produce the ultimate painting, but a modification of the meaning/effect of the painting when viewed in its final form. Furthermore, despite the fact that the painter could not subsequently provide an explanation for the effect of the color alteration, the dream still constituted a trigger for developing sound inferences. His unexpected mental depiction alone intimates the efficacious effect of the change upon the whole of the painting, in that it "flashes the new suggestion before our [the painter's] contemplation." (1903: EP2, p.192). The upshot of these unbidden, creative hallucinations is to supply the necessary result, together with a viable resolution. The resolution entails a concerted plan (though the plan need not be conscious/intentional) to continually update previously acquired objective knowledge with both sense data and insights gained idiosyncratically. Hence, creative hallucinations are the ultimate proponents to develop workable inferences and to act them out as behavioral propositions, since they draw upon both bidden and constructive sources.

\section{Cognitive factors influencing dreams}

For Peirce, the function of dreams in inference-making is indisputable. While some dreams need to be ignored or discarded, others, if their import is recognized, can lead to critical discoveries. "Dreams are not mere idleness". In other words, the substance and import of particular dreams, which bypass the non-veridical assumptions emanating from obsessional or socially biased glimpses, constitute dreams that can have a meritorious effect upon our logical system because their propositions and assertions, i.e., claims to which we commit, supersede subjectively derived assertions. While some of these dreams surface instantaneously in the mind, seemingly without the need for perceptual input, others arise consequent to constructive mental plans/designs (dream functions 2, 3, 5 and 7); they can culminate in creative hallucinations. As such, dreams from both sources form the basis for new discoveries:

Day dreams ${ }^{3}$ are often spoken of as mere idleness; and so they would be but for the remarkable fact that they go to form habits, by virtue of which when a similar real conjecture arises we really behave in the manner we had dreamed of doing. (1893: 6.286)

Peirce indicates that if the dream has some specific potential for implementation, such that it arises from virtual habit, its effect on lasting action and behavior schemes is maximized. Here

\footnotetext{
${ }^{3}$ Peirce's use of the term "day dream" here presages his use of "creative hallucination" in 1903.
} 
vivid dreams, such as those found in the seven dream functions serve as imperatives given their clarity, salience and self-propelling imperative effectives (1909: MS 620). These vivid dreams (virtual habits) constitute catalysts, inciting children to implement the dream into a logical remedial set of real events. Essentially, the moving icons present in Peirce's fifth dream function become the substance of the virtual habit, ultimately propelling newly envisioned conduct into real world scenarios. The component of self-control for implementation of the dream deriving from the seventh dream function makes relevant determinations in the fifth dream function to ultimately create modified action habits and to recommend novel courses of action for previously unexplained consequences. These recommendations (1909: MS 637), increasingly maintain a deictic character first commanding the self to new habit affecting consequences, then incorporating recommendations for others to do so based on their particular proclivities. The diagrammatic character of the moving verb-dream qualities qualifies them as informational indexes such that particular places, participants and times (deictic elements are incorporated into the logical relations of events. These dreams ultimately reveal the necessity to search out plausible inferences for seemingly new outcomes; their diagrammatic character as informational index (icon and index together) suggests conditions that are ripe for searching out alternative logical relations between events.

In support of the instrumentality even of unbidden dreams to abductive reasoning, Peirce claims that certain sudden vivid images, although unplanned, can significantly alter meanings associated with ontological relations, e.g., cause-effect determinations originally accorded to preconceived event templates. This is especially germane early on in development, since putting aside assumptions that co-occurring events are causally connected is especially challenging. Ignoring direct experience of coexistent events in favor of unseen influences requires higher level cognitive skills, chief among them decentration and perspective-taking (Piaget, 1961/1969, p.327). Children's assumption that the presence of a clown at a party necessarily caused balloons to burst is but one example of the riveting effect of co-occurring events on children's attempts to form logical relations, despite the often obvious irrelevance of the events to one another. When children call upon an unbidden insight, e.g., the influence of a latent factor affecting the balloons' destruction (something atmospheric), their inferences can reflect more objective, sound propositions and assertions, because they do not rely upon misleading often subjectively perceived data. Gibson's (1979, p.261) discussion of the inferiority of external stimuli and language to lead children and adults to truly resourceful conclusions extends Peirce's perspective still further, it privileges subjectively derived ingenuity in the form of specific mental pictures in the mind which, when acted upon, have the potential to renovate beliefs and practices.

Nonetheless, the process of using pictorial innovations to revise practical logic follows a rather lengthy developmental course, since it often requires children to ignore sensory data and what other children think, in favor of accepting less obvious (more objective) influences. Children must likewise wait until surprising/anomalous consequences arise before they have the impetus to search for different, hidden explanations. Furthermore, they need to decouple to hold and integrate a minimum of two images in their mind, without being hypnotized by perceptual salient factors, which might prove to be irrelevant. This process depends upon utilization of constructed object files which cohere object attributes within the same mental construct. This capacity begins with the object index at 6 months (Leslie and Káldy, 2007, p.117). The attribution of index to object files is foundational to manufacturing sound inferences, because knowing the object's place often indicates where 
and when to expect its reoccurrence and later to decouple the place from the object, in order to more objectively isolate factors associated with that object. This decoupling of location from object marks the beginning of deictic facility and establishes novel event templates/relations across events consonant with Peirce's fifth dream function. Likewise foundational to decoupling (beyond the index file) is establishment of object files. In the object file, children include qualitative object characteristics beyond location. These more qualitative object attributes become integrated into the object file at approximately 8 months; they include: color and shape (Oakes, Ross-Sheehy and Luck, 2007, p.85).

Given that at this early stage in development, children's inferences must be measured via non-linguistic behavior, their natural responses to unforeseen object disappearance and reappearance in different spatial and temporal contexts is quite instructive. One experimental paradigm entails investigation of object permanence in which objects are either partially or entirely hidden. Expectations are to measure differences in infants' performance, e.g., they look longer at reappearing objects or they uncover occluded or semi-occluded objects. The rationale is that if children expect the object to disappear or reemerge from the particular location/circumstance (consequent to the contents of their object file), but the object does not, they are more likely to search/abstain from searching for the object. In other words, either the emergence or absence of an object in a particular context constitutes the surprising event, This response begins to surface as early as 3.5 months (Baillargeon, 1987, p. 662) when infants' looking time increases (indicating surprise) upon an object's emergence from behind a screen. Further advances though, in reach-and-find behaviors illustrate the application of new relational templates pre-established object files (Leslie, Xu, Tremoulet and Scholl, 1998, 13). The new relations derive from novel vivid verb-dreams, which virtual habits afford. Afterward, when Peirce's seventh dream function operationalizes the image into remediative conduct, dreams begin to markedly affect children's ontology, and ultimately influence their expectations about which events legitimately contribute to consequences.

Inferencing from surprising consequences continues to surface when children become ambulatory. The object file of ladders, for example, first entails their location, then encompasses climbing different kinds of ladders in different locations. An unexpected consequence of ladder-climbing, leading to a revision of the object file and construction of a new verb dream (Peirce's dream function 5) might entail falling between rungs, such is likely to evoke some feelings of apprehension, or at very least, surprise. As a consequence, a picture in the mind of an action accommodating many kinds of ladders could instigate both new habits of acting upon open and closed steps, e.g., using the hands for support, or gripping with the feet. Novel envisagements of how to act upon absent or partially absent objects is likewise subject to habit-change from new object envisionments. Such can begin with the surprising circumstance of accidentally crawling over a pet's tail when it is under a sofa; and the definite image informing subsequent inferencing is the holistic mental picture of that pet in an injured state. This image attached to a new action/verb dream, which flashes in the mind, forms the basis for the inference that even unseen objects or portions of objects can still be directly affected by unintended actions. This illustrates decoupling, in that simultaneous visual access is no longer a requirement for existence even for present objects. What is decoupled is direct physical exposure from the knowledge that the hidden object can still experience effects.

Once joint attention emerges at 1;2 (Saylor, 2004, p.608; Baldwin and Saylor, 2005), more socially based dreams (hallucinatory, constructive) become possible; and it is the deictic processes dreamed of in virtual habits that accounts for this more objectivized 
perceptual logical system (West, 2013, 2016b, 2016c). Ordinarily this is accomplished via indexical gestures and language for expediency of communication, e.g., the child pointing/gazing at a ringing telephone, then at the adult while uttering "wake up?". Here the child is analogizing the sound of the alarm clock with that of the telephone (see West 2013: chapters 2 and 3 for a further discussion of the utility of indexical gestures in ontogeny). The implied inference on the part of the child is that index (pointing, gaze) constitutes the deictic tool to redirect others' focus to that of the child. Index then becomes an effective instrument for issuing imperatives to others, and perhaps also to the self, as well-illustrating the power of Peirce's seventh dream function: self-controlled imperatives.

Nevertheless, like the effect of language upon inferencing (Gibson, 1979), dreams which lack veridicality (as in Peirce's social hallucinations), can bias children, such that their dream-like pictures are unlikely to give rise to plausible inferences, because they lack a deictic character. In the absence of a deictic character (i.e., the appreciation of different event participant perspectives), dreams as social hallucinations consist in a malformed subjective perspective which in turn violates logic, given that it does not represent how others perceive event relations. Accordingly, knowing what others think (if the perspective of the other is non-veridical, can easily serve to disadvantage children, since thought then becomes a process of blindly accepting their assumptions without weighing them against other veridical ones, or of embracing societal norms (Gibson, 1979, p.261-264). If a party to an exchange invents unexpected conclusions (as is often the case in pretend scenarios in which false belief prevails), the involved child is vulnerable to unquestionably adopting the same, especially if the social dreams are not decoupled such that events can have differing contributory weights in distinct scenarios. The lack of decoupling is especially obvious when distinct contexts are ignored, and when the adult's conclusions (which likewise ignore context) are contrary to social or logical norms but are, nonetheless, adopted as the child's own, as in the "naughty teddy" experiment (Harris and Kavanaugh, 1993), described in Section 5.

Another illustration of how decoupling advances children's more creative dreams toward generating abductions is the substitution of one object for another, e.g., using a pencil as a hammer (Harris, 2000, p.35) and a banana as a telephone (Piaget, 1945/1962; McCune, 1995, p.206). The mental images that permeate object substitutions reveal the presence of underlying iconic representations. Object substitution demonstrates a decoupling process, in that labels that are typically associated with a particular object are given less conventional applications - the word is associated with a new context and novel set of virtual habits (imminent action relations). These object substitutions qualify as abductions given the attribution of unconventional, but not non-veridical object uses. These newly conceived-of uses derive from Peirce's third and fifth verb-based dream functions, in that they propose, via virtual habit, new ways of problem-solving and interacting with objects. It must be recognized that the emergence of joint attention does not merely bias or depress children's individual efforts to inference-make; it likewise can hasten determinations of the viability of subjective images through announcing and clarifying their potencies, in line with a Vygotskyan approach. For these reasons, the emergence of joint attention establishes a practical playing field for determining the plausibility of inferences which surface from subjective envisagement - "let me try this out on you!" Consequently, it is no accident that they (joint attention and object substitutions) are co-dependent cognitive skills, given the impetus that reciprocality/reciprocity provides in creating plausible inferences and expressing novel analogies. Showing a potential rationale to another (orchestrated by attentional indexes) provides further impetus for revising abductions - supplying specific purposes for 
making what had initially been implicit rationale (within the child's own logical system) explicit for another. In the process of making explicit propositions to an interlocutor, the need for children to refine their use of attentional indexes becomes critical. To subtly communicate propositions to other minds requires knowledge of rudimentary propositions/assertions held by those minds. In short, proposing a new direction, that attending to a different object/event has merit, necessitates some elementary appreciation for whether the implicit rationale for the child's focus will have sufficient value for the other. Accordingly, to convince another of the worth of joint focus, children must apprehend that their image/dream has the potential for perspectival sharing. This more deictic skill entails an evaluation that the child's implicit proposition has the logical strength to be viable on a more objective plane.

\section{Further developmental factors}

Although social hallucinations still control children's reasoning even at $1 ; 8$, in view of the intersubjective nature of early input, their reasoning appears to gradually be tempered by decoupling proper (Leslie, 1987, pp.419-420). Decoupling is a cognitive skill that monitors the degree to which factors/features of an object are essential when they are instantiated in particular event structures. These structures include both the physical context, as well as the nature of the motivation that perpetuates the event's actualization. Decoupling is essential in constructing the kind of Peircean dreams that can result in viable inferences, given that nonessential features of objects/events need to be dissociated from the contextual features which they often appear. Peirce's virtual habit can vividly supply diverse objects in different contexts, all of which may produce a similar unexpected consequence. Here, abductions surface from dreams which envision new ontological and interactional relations, as set forth in Peirce's third and fifth dream function. What alters is the interpretant of the object-sign connection (the meaning/effect), in light of the additional fact that applying particular features to other objects in similar event structures can augment meanings of similarly situated objects. The upshot is that the feature deemed to be non-essential (but not irrelevant) to the essence of an object is likewise unnecessary to the event, or to its perceived consequence.

Accordingly, latent contributions afforded to events via the addition or subtraction of features, need to be considered, not only those features which are frequently instantiated. The collective memories of objects and their event structures do not emerge from conscious deliberation; rather, as Peirce contends (1909: MS 620), sudden vivid images surface which flash in the mind as unbidden insights to inform the logical system and to revise inferences. ${ }^{4}$ Accordingly, dreams can represent new relations between objects, events, and consequences in that they uncover the non-essential features of each by deleting them or replacing them with those which have more objective utility, incorporating a deictic framework. Features which are non-essential need not define an object altogether, but can be imported to other objects/genres via virtual habits housed in "eidetic memories" (Bühler, 1934/1982, p.28); and these vivid dreams are often the source for more innovative sound judgments.

\footnotetext{
4 "The abductive suggestion comes to us like a flash. It is an act of insight, although of extremely fallible insight." (1903: 5.181)
} 
Decoupling can be measured both linguistically and non-linguistically - provided that the behavior indicates the degree of detachment between the feature's appearance and the element of surprise. Surprise illustrates children's implicit inferences; but surprise to both perceptual and non-perceivable causes must be examined to tap children's state of decoupling. Non-linguistic evidence ordinarily entails use of gestural indices, e.g. pointing to the place of an absent object, while gazing at a familiar person, without disqualifying the event from its predetermined status by virtue of the object's absence. Employing deictic devices (attentional cues directed toward interlocutors and to typical locations of absent objects) reveals that the child has implicitly inferred that the object's absence does not indicate lulls in existence; rather, surprise upon the object's materialization illustrates the expectation that the object is unnecessary to that context, and can be decoupled (redirecting inferences). As such, direct visual perception is assumed to constitute a non-essential feature of that event. In short, newly constructed mental images can constitute both decoupling, as well as inferencing, when the surprising fact of the object's reappearance/failure to reappear leads children to use a different noun to refer to more than a single object, e.g., moon for doorknob. This form of decoupling results in novel application of a physical characteristic (shininess, orbital shape) from tangible door fixtures. Here children operate on the notion that shape, glint and direct interaction are non-essential characteristics. In short, the absence of shininess or round shape ultimately does not disqualify non-shiny fixtures from status as knobs.

Establishing what qualifies as existent via inferences may not initially include absent or partially visible objects; but, after establishing through vivid dreams that certain objects can exist without being observed (decoupling), more sound inferences result (consequent to revised assumptions). To illustrate: the absence of a cookie jar may initially result in the assumption that cookies are not likely to be forthcoming - the event not qualifying as a snack; but either after observing cookies in alternative conveyances, or other goodies being served, inferences can be revised such that the event still qualifies as a snack. In short, new vivid action-dreams embodied in physical indexes (gazing and/or pointing to the substituted conveyance/snack), hasten revisions of previously established inferences for particular sets of objects/events - events are decoupled from their non-essential objects when anomalous instantiations of events surface unexpectedly, and when children determine, via revised inferences, which objects are essential to that event. Inference-making then constitutes a process of reconstructing alternative pictures of events, which, after reconciling previous propositions with newly conceived ones, result in revised foundational hypotheses.

The second and third dream functions, which are iconic in nature, are particularly relevant in both drawing similarities (which are never exact copies of the original) and in decoupling features of the original from their replicas. This is particularly poignant in Peirce's third dream function which specifies that verbs (as characterizing events are "mere dreams" in that they are imaginations "unattached to particular occasions") verbs have the character of a mere dream in that they apply to different participants, locations, and times; and implicitly refer to events as general event types, e.g., give including any agent, any receiver and the transfer of any sought after object. Peirce's fifth dream function is illustrated once children begin to construct more novel event relations, such that events supersede single actions to include states of being/affect. Children's eventual means to construct single events into sequential episodes further demonstrates the refinement of Peirce's fifth dream function between 1;0 and 2;0 (Bauer, 2006) - to apprehend novel sequences within events as in removing, shaking out, and replacing a mitten on a puppet's hand (Barr, Dowden, and Hayne, 
1996). This relational based event dream function is operational at $1 ; 9$, when infants recognize an event as being the same as an original event independent of the substitution of an agent e.g., duck puppet for cow puppet (Hayne, MacDonald, and Barr, 1997). The relational dream is tantamount to decoupling the original puppet and perhaps other locational features, and allowing deictic substitutes to legitimately serve in the same episode, e.g. other agents (receivers) or other action episodes.

Additional evidence that decoupling continues after 2;0 is obviated in children's use of nouns for absent objects - objects/persons which are absent from direct observation. Sachs (1983, p.5) reports that reference via names/common nouns to absent objects emerges at 1;6, slightly later than do object substitutions. Sachs' findings demonstrate that expectations of object displacement entail higher level inferencing when compared to those which ascribe unconventional features to objects. In the former (object displacement), features are suddenly confiscated/hidden from the context, while in the latter (ascribing unconventional features to objects) the characteristic under scrutiny is still physically present. For object substitution, an indexical association can facilitate a novel event applied to a present object. Associating novel events with displaced objects relies upon implicit, indirect memory sources. In other words, displacing objects requires children to construct an alternative mental picture of the original context, excising what was once considered to be an essential object/attribute. This mandates children to engage in a form of logical contradiction, whereas in object substitution children only need to enlarge the object set to which an attribute applies - a far less complex process. This more easily achieved skill of object substitution surfaces in diverse cultures/languages - indicating reliance upon a rather universal and more basic competency. For example, Huli children use "root" to mean "sweet, and potato" or their word "snake or potato" for "water" (Goldman 1998: 66, 76). Using "potato/snake" to refer to a different object altogether (water) reveals the non-essential nature of physical characteristics such as shape and/or density.

Accordingly, dreams which entail decoupling can renovate inferences about objects/events such that instantiations of objects/events which were initially contradictory acquire new identities, enlarging object concepts with which the feature is associated. Use of the same proper name for different humans/animals, as McCune (1995, p.204) reports, demonstrates just how critical naming is in facilitating the decoupling process. Apprehending that proper names represent non-essential features with respect to persons to whom they refer is critical to an awareness that they have equal potentiality for assignment to other individuals. Meeting a person who bears the same proper name as a family member, but who does not resemble that relative, constitutes an unexpected event from which revised dreams surface. In turn, children come to incorporate into their related inferences that certain physical/personality characteristics are not essential to any particular proper name.

\section{Pretense as a forum for the emergence of hallucinations}

Social hallucinations often still dominate at two years when decoupling becomes less operational in favor of unquestioned acceptance of others' interpretations of what is transpiring. This is supported by findings from an experimental pretense paradigm (Harris and Kavanaugh, 1993), in which two and three year old children were expected to align their perspective with that of an adult by resolving an accident scenario that did not actually materialize, but which did not entirely defy possibility. In the Harris and Kavanaugh study, 
children observed a teddy pouring pretend tea from an empty tea pot onto a toy pig. Afterward subjects were asked whether the teddy was "naughty," and why. Even the two year olds reported that the teddy was in fact "naughty," although no clear rationale was supplied. Both two and three year olds actually acted upon the experimenter's perceptions of the consequences, by attempting to dry the pig with a towel. It is evident that the emergence of false belief after two years, which these findings indicate, appears to rest upon increased deictic skills, adopting another's interpretation which is contrary, but not impossible, when compared to the actual event. To align themselves with the adult's perspective, children construct a "moving picture" representing the adult's rendition of the scene. Adopting analogous but unconventional object use, such that children agree that appearances conform to conventions when they do not, illustrates implied inferences.

Instantiations of false belief continue to demonstrate both social and obsessional hallucinations and the implausible inferences predicated upon them even later in development. Nonetheless, when children begin to enact their virtual habits through role-play after 3;0, their dreams go beyond automatically adopting altogether another's envisagements and beliefs as their own. Although dreams are still packaged as pretend scenarios, the character of the dreams is not reproductive (entirely iconic) in nature when compared with perspectives from influencing adults. The more constructive process of Peirce's fifth dream function can take them beyond conformity to sameness of events; instead, events emerge from moving deictic verb potentialities, which coordinate new relations, especially when vivid in nature. In fact, once children have committed to the soundness of a dream as a virtual habit, they act it out by implementing it in action schemes via role-play. The component of acting out wishes reveals underlying inferences about how to make the particular event happen. It demonstrates that children perceive their assumptions (although not an exact replica of others' assumptions) to be sufficiently objective to qualify as legitimate to observers. In fact, inclusion (in children's images) of an expected object (when the object is absent from the scene) evidences that their dreams are more than replicas of adult icons. Moreover, children's constructed dreams are associated with interpretants/meanings which often do not match those of adult partners, as demonstrated in the inferences that propel their enactment.

For example, inferences underlying role-play of a particular cat's behavior (meowing, crawling on all fours, slurping milk) is presumed to transport a desired absent friend into the present context (Harris, 2000, p.35). This form of role-play derives from dreams supported by implied inferences. These inferences consist of children's settled belief that production of the cat's observed conduct can make the sought-after animal reappear. In other words, children's inferences (however misplaced) are constructed upon the assumption that role-playing of the essential characteristics of the desired object is sufficient (and perhaps even necessary) to rescue the kitty from absenteeism. Here, children's dreams fueled by constructed inferences are presumed to allow access to the sought-after friend. The underlying inference emerges consequent to both social and obsessional hallucinations, in that children's logic is predicated upon emotions/desires to transport the previous surprising and pleasurable experience with the kitty to here and now experience, by actualizing their mental icons of what the events should be. This enactment of the dream bids the event to materialize, despite the obvious logical impossibility. In short, by sheer enactment of desire via role-play (drawing from Peirce's seventh dream function, action imperative), children change outcomes. They can, as Peirce determines (1911: MS 674, p.15), command that individuals/events be made virtually accessible if they are absent. 
Public Journal of Semiotics 7 (2)

As stated earlier, Peirce not only anticipates the influence of dreams on belief structure and their implementation into action (1911: MS 674, pp.14-15), he demonstrates the process necessary for commanding the self to put into practice actions that demonstrate the underlying inference. Peirce shows how the process is guided by the conscious and deliberate exercise of controlling one's feelings and reason, such, that the two do not conflict with one another. The process which Peirce determines to be responsible for the unification of feelings and logic is hypostatic abstraction. Hypostatic abstraction secures one's attention to a narrow feature/issue, facilitating a closer alignment between feelings and action. This is orchestrated by narrowing the focus, and, as such, by limiting sources of stimulation (1903: 1.383). It does so via what Peirce calls prescinding (W3, pp.49-59) - deliberately replaying a small segment of the event before the mind, such that focus upon a minute sensation and response clarifies how what might be ignored as trivial at first glance, may actually have a greater influence on an event's outcome. In this way, prescinding functions early on in development to increase the notice of minute details of objects/events, leading ultimately to uncover some potential, latent influences, with the result that children cultivate more sound inferences. In short, children can orchestrate their own training to become little experimenters - by consciously considering whether individual attributes (which may not be obvious) may, in fact, be essential to create particular event outcomes.

\section{The function of deictic skills}

Although decoupling via object/word substitutions and early role play enhance notice of the contribution of more latent features to outcomes, they serve merely a consciousness-raising function. Decoupling allows children to prescind what is obvious in their own experience, without the benefit of more objective, other-centered exchanges. Nonetheless, to generate novel inferences from truly creative hallucinations, children must embrace points of view beyond parochial ones, because weighing how acceptable their proposed premise might be in more objectified scenarios (from distinctive vantage points) is critical. Working out success within alternating frameworks (conversational, social, logical) provides a forum to develop the kind of foresight necessary to see the unseeable - to forge outcomes by uncovering primary influential factors. To forge successful outcomes, particular linguistic skills are paramount, chiefly conversational competencies, e.g., integrating semantic and pragmatic factors- productive use of speaker/listener pronouns (West, 2011b, p.95). Mature pronoun use relies upon intrinsic knowledge that speaker is semantically encoded as $I$, and listener as you, in addition to the recognition that these pronouns allow for referential latitude - that diverse individuals can assume such roles (West, 2013, Chapter 2). As these pronouns establish slots that monitor speech and event contours, they foreshadow narrated event slots, e.g., agent or receiver.

Likewise, constructing creative dreams that lead to abductions rests equally upon four distinct, and active socio-cognitive experiences: (a) legitimizing one's place in an exchange (linguistic or otherwise), (b) negotiating one's path into an event role, (c) deciding whether to take that role, and (d) how to maintain it (which requires knowledge of when to abdicate in favor of another's assumption of that role). As such, reconciling the diversity and reciprocality of individual perspectives (physical, affective, cognitive) with factors arising in interactive settings is paramount before dreams can truly reflect the objective/invariant character necessary for reliable inference-making. Switching conversational partnerships 
affords experience in diverse event roles, such as: agent, patient, receiver, and benefactor). This process begins at approximately three years of age, with productive use of the pronouns I, me, my, and you (West, 1986, p.115, 2011a, p.159, 2011b, p.95). These pronouns both encode speaker/listener roles (following their alternations in the conversational context), together with participant event roles.

Participant alternations within events are stored as episodes; as such, their character as dreams draws upon Peirce's emphasis on verb relations (i.e. dream function 5). Verb productivity is especially obviated when the same verb is employed with distinctive agents, receivers, etc., and when verbs with similar semantic content surface interchangeably. According to Tomasello and Brandt (2009, p.113), production of different kinds of verbs demonstrates how children name different events, how they then identify and classify both actual and possible happenings. This is evident in the fact that intrinsic in event classification is apprehension of the kinds of participants which events are likely to feature, e.g., give requiring three participants as arguments: agent, instrument, receiver. These event slots codify event direction (how events play out/their outcomes); and they trigger the inception of holistic vivid virtual habits depicting such directional slots. The directional character driving vivid mental icons can likewise emanate from the verb's lexical content itself, e.g., learn specifically mandating human/animal agents/experiencers with a complement/complementizer; and from these dreams children derive the raw material for reconstructing more viable dreams (creative hallucinations) which contain predictive foresight into the limitations and elasticity inherent in particular event types.

In fact, the nouns (arguments) that children attach to particular kinds of verbs, are likely to represent an event type/template more than one event. Accordingly, productive use of novel verb templates or those fitting into previously constructed templates establishes the slots into which event participants are fitted. In other words, expanding names for events, by using additional verbs expressing agency, instruments, and receivers (e.g., explain, lend, guide, offer, engage, in addition to give) extends the kinds of participants which can serve as the agent, e.g., humans, animals, other animates, inanimates. In fact, children's apprehension that it is not beyond the realm of possibility to incorporate non-humans as agent in a transferbased event role constitutes a verb use which is likely to prefigure extending the event paradigm itself.

With the creation of imaginary companions at 3;0, further deictic competencies are developed. Acting out these scenarios demonstrates how, via beliefs derived from mental images, children displace individuals from their typical contexts and transport them into other, possible worlds. The effect of filling empty event slots as vivid images in the mind, then guides when and how absent "friends" are configured in events; this creates practical contexts for inserting imaginary persons and for determining how they might think, feel, or behave in those events. In this way, virtual habits depicting others' interactions with the self sharpen predictions regarding how imagined persons (even unfamiliar ones) will act. These virtual habits provide an impetus for guessing reactions in potential outcomes. In short, implementation of imaginary friends into a known context establishes a playing field in which inferences are sufficiently deictic that they fashion possible worlds. Accordingly, children can import novel perspectives (those never before injected into the scene, e.g., at home), while holding the physical context constant. As such, the physical context, as well as aspects of the social context, serve as a stabilizing template within which imaginary personages, e.g., clowns, complete the dream. 
According to Ames and Learned (1946, pp.154-157) two-year olds begin creating invisible friends when they impersonate familiar persons/animals apart from the presence of those individuals and apart from the spatio-temporal environments in which they have experienced them, e.g., barking at and biting people like a friend's dog. These impersonation episodes are ordinarily brief, not lasting more than a few minutes/hours. In view of the abbreviated nature of these iconic, directional activities, together with the more imitative nature of the reproductions, they should be classified as proto-representations - not authentically imaginary (Taylor, 1998, p.25). According to Taylor (1998), to truly imagine invisible friends, children must transcend mere imitation (reproduction of the exact behavior), and must role-play conduct which is anticipatory of the "friend's" behavior over several days/months/years.

As Harris (2000, p.35) claims, children must have at their disposal, a theory of mind which supersedes appreciating thoughts and feelings of familiar persons. They need to apply known tendencies to made-up individuals, such that thought/feeling are newly attributed to companions other than known personages (family members, pets). Ames and Learned (1946, p.154) report that between three and five years of age, this is operational, although it becomes truly anticipatory of potential feelings/perspectives during the latter half of this developmental interval. The authors document a case of a child pretending that two clowns resided with her (sleeping in the guest room) and the child is reported to have become quite agitated upon the arrival of family guests. The child's agitation reveals her ability to envision a likely consequence of the unexpected arrival of family guests. Her agitation illustrates her ability to foresee the clown's feelings of dejection upon not being afforded a place to sleep. This ability to foresee feelings demonstrates competencies beyond mere physical consequences; it reveals some means to take a would-be perspective in an unrealized circumstance. In short, bringing into existence imaginary friends at 3;0 and thereafter illustrates how children go beyond merely holding a picture in the mind; it reflects how children embellish upon static icons, as in Peirce's third and fifth dream functions, staging them in new places and times from their original experience. It shows how children construct a system of conjecture - predicting future attitudes and conduct, in light of earlier habits.

The character of this role-play is deictic; it is both durative and dynamic demonstrating an extension of a single iconic snapshot to create a more holistic active hallucination. This kind of hallucination is exemplary of Peirce's creative hallucination, in that it not merely integrates the iconic with an indexical component, but incorporates wouldbe persons and worlds, reminiscent of Peirce's notion of "virtual habit" (1909: MS 620, pp.24-25, W2, pp.227). In this way, children construct action sequences from memories, altering predictions of consequences to unrealized participants. The indexical component is exemplary of the predictive nature of this dynamic role-play, since both the coexistence of events and their sequences ordinarily insinuate logical relations between events and the players that participate in them, especially early in ontogeny. In short, deriving logical relations from dreams of physical locations and happenings, however implied, evinces conjectural templates in the mind, which result in hypothesis-making of these templates and their enactment in possible worlds. As such, imaginary play (as opposed to impersonation) illustrates children's development of theory of mind - demonstrating others' perspectives, often foreign to egocentric viewpoints.

Unexpected consequences can facilitate anticipation of others' perspectives/responses, and can serve as the catalyst to generate objective, sound predictions explaining how the self or another might feel and act in subsequent circumstances. To illustrate, earlier advice to 
avoid certain conduct for safety reasons may be recalled, accessed, and implemented upon exposure to a similar potential but unexpected danger, e.g., refraining from tipping one's chair back, given the eventuality of falling/splintering the chair altogether. More advanced perspectival skills entail apprehension of others' potential plights, e.g., exposure to teammates' diverse reactions to preclusion from playing in a game, from either an injury or poor performance. However, greater sensitivity to players' feelings of misfortune may not materialize until surprising reactions are revealed by experiencing the same misfortune sitting out the game. Resultant virtual habits might consist in envisioning, different less fortunate teammates sitting out in future games, or the good fortune of participation after improved health/performance. These dreams have a creative character, in that they do not result from self-experience alone, but from projections of how others are likely to react in subsequent scenarios, in light of past habits. The objective character of Peirce's virtual habits is such consequent to its deictic quality-relating events through incorporating diverse places, participants, and temporal frames.

By allowing for deictic shifts, predictions of outcomes in possible worlds, in going beyond self-experience/others' past habits, such dreams rely upon what Tulving (2002; 2005: $35)$ refers to as "time travel" or "autonoetic" consciousness. Tulving's $(2002,2005)$ findings demonstrate that this skill only develops after four years of age, when children are able to supply coherent descriptions of vivid, past events at times and in places apart from the original happening (Pillemer and White, 1989, pp.315-316; Pillemer, 1992, p.254; Perner and Ruffman, 1995, p.540). These findings support the fact that after 4;0 children can articulate the factors that contributed to a certain event, and can likewise begin to determine likely consequences were similar eventualities to materialize (both for the self and for others). Nonetheless, children's recall of these consequences to apply to would-be future events depends chiefly upon the vividness of the mental image (Neisser, 2004, p.156), together with the acquisition of more advanced deictic skills. Tanz (1980/2009, pp.50-51) reports that comprehension of place deictic skills, i.e., the means to choose "this" or "that" object even when perspectives conflict, does not surface reliably until nearly five years of age, when children were able to reliably determine that the near object for another might well be the far object for the child. These findings, together with those of West $(1986,2011 \mathrm{~b})$ from younger children, suggest that children must first project themselves into another's point of view in actual contexts before anticipating what others might see/feel in future contexts. These deictic competencies make possible more specific snapshots featuring different objects/persons/timeframes in the same event structure. As such, they are foundational to the decoupling process-inhabiting the element of habit change necessary to qualify as abductions.

\section{Conclusion}

The place of dreams in fashioning sound inferences is far from insignificant, especially for children, and Peirce's account makes this plain. When dreams take the form of specific kinds of vivid, soon to be implemented, virtual habits, they qualify as abductions - recommended courses of action for the self/other. According to Peirce (1911: MS 674, pp.14-15), the early influence of prescinding (in Firstness) on the refinement of sound inferencing culminates in imperatives to the self. The continued influence of creative hallucinations in framing sound inferences later in development shows that dreams, either unbidden or constructed, can 
indeed contain the seeds to propose sound explanations for happenings. The pragmatic effect of these dreams cannot be overstated. Peirce is adamant that although these creative dreams have practical relevance to propose modes of action, they must be grounded in possible worlds, not in scenarios which are remote or that can never be actualized.

Accordingly, dreams supply insights into how potential happenings materialize identifying which factors can enhance/enrich the effectiveness of potential event outcomes. Nonetheless, the dream/hallucination must be of a particular character. Dreams of this creative kind are not obsessional or socially driven (1898: EP2, p.192); instead, they form the bedrock for conceiving of many meritorious insights. The process of altering insights that come to the mind as vivid mental images does not stop with prelinguistic habits, word substitutions, overextensions or role-play. The rather prolonged process of appreciating and objectifying allocentric perspectives renovates children's rendition of the structure and contribution of individual events to their outcomes. To do this, children switch perspectives via productive use of deictic terms. As a consequence, their state of logic advances, such that perspective alternations supply practice in seeing what others see as contributing to unexpected consequences. Children's adoption of alternative roles provides frameworks for expanding and limiting recurrent event templates, such that assuming alternative roles precludes the possibility of exceeding limits into the impossible. In this way, the viewpoints/factors which children propose to have influenced event outcomes are less likely to be unsound, random or spurious, because they acquire a non-subjective character. Hence, ensuing inferences are more likely to constitute the most plausible abductions.

After four years of age, dreams become more dynamic, embodying Peirce's notion of creative hallucinations. At this juncture, iconic dreams advance status to envisioning moving verb relations, and depict innovative paths to account for unexpected phenomena. The dreams that qualify as creative hallucinations exert formidable (ordinarily vivid) impressions on the mind, the substance of which propose new avenues for future conduct and "recommend a course of action" (1909: MS 637, p.12). As such, the image of actual experience can be altered (qualifying as a would-be) because children role-play diverse persons with diverse meanings, injecting other participants into event scenarios whose physical and psychological orientations may conflict with original ones. In this way we can appreciate Peirce's directive that dreaming dreams is the foundation for inference-making through consideration of diverse viewpoints. In short, Peirce leaves us with the following claim: "intellectual value of a present thought lies in what this thought may be connected with in representation by subsequent thoughts -which renders meaning altogether something virtual" (W2, p.227). This "virtual" is nothing short of the ultimate character of deictic shifts sprung from the seeds of virtual habit.

\section{References}

Ames, L.B. \& Learned, J. (1946). Imaginary companions and related phenomena. Journal of Genetic Psychology 69, 147-167.

Baillargeon, R. (1987). Object permanence in $31 / 2$ and $4 \frac{1}{2}$-month-old infants. Developmental Psychology 23(5), 655-664. 
Baldwin, D. A. \& Saylor, M. M. (2005). Language promotes structured alignment in the acquisition of mentalistic concepts. In J. Wilde \& J.A. Baird, (eds.), Why Language Matters for Theory of Mind, (123-143). Oxford: Oxford University Press.

Barr, R., Dowden, A., \& Hayne, H. (1996). Developmental changes in deferred imitation by 6- to 24-month-old infants. Infant Behavior and Development 19, 159-170.

Bauer, P. (2006). Constructing a Past in Infancy: A neural-developmental account. TRENDS in Cognitive Sciences 10(4), 175-181.

Bellucci, F. (2014). Logic, considered as Semeiotic: On Peirce's Philosophy of Logic. Transactions of the Charles S. Peirce Society 50(4) 523-547.

Bühler, K. (1934/1982). The deictic field of language and deictic words. In R.J. Jarvella \& W. Klein (Eds.), Speech, Place, and Action: Studies in Deixis and Related Topic, (930). Chichester: John Wiley \& Sons, Ltd.

Colapietro, V. (1988). Dreams: Such stuff as meanings are made on. Versus 49, 65-79.

Gibson, J.J. (1979). The Ecological Approach to Visual Perception. Mahwah, NJ: Lawrence Erlbaum Associates.

Goldman, L. R. (1998). Child's Play: Myth, Mimesis, and Make-Believe. Oxford: Berg.

Harris, P. (2000). The Work of the Imagination. Oxford: Blackwell Publishers.

Harris, P. L., \& Kavanaugh, R. D. (1993). Young children's understanding of pretense. Monographs of The Society For Research In Child Development, 58(1), 1-92.

Hayne, H., MacDonald, S., \& Barr, R. (1997). Developmental changes in the specificity of memory over the second year of life. Infant Behavior and Development 20, 233-245.

Hintikka, J. (1998). What is abduction? The fundamental problem of contemporary epistemology. Transactions of the Charles S. Peirce Society 34(3), 503-533.

Kilpinen, E. (2016). In what sense is Peirce's habit-concept revolutionary? In D.E. West and M. Anderson (Eds.) Consensus on Peirce's Concept of Habit: Before and Beyond Consciousness, 199-214. Heidelberg: Springer-Verlag.

Leslie, A.M. (1987). Pretense and representation: the Origins of "Theory of Mind." Psychological Review 94(4), 412-426.

Leslie, A. \& Káldy, Z. (2007). Things to remember: Limits, codes, and the development of object working memory in the first year. In Lisa Oakes \& Patricia J. Bauer (Eds.), Short- and Long Term Memory in Infancy and Early Childhood, (103-125). Oxford: Oxford University Press.

Leslie, A.M., Xu, F., Tremoulet, P.D., \& Scholl, B.J. (1998). Indexing and the object concept: Developing "what" and "where" systems. Trends in Cognitive Sciences 2, 1018.

Magnani, L. (2001). Abduction, Reason, and Science: Processes of Discovery and Explanation. New York: Kluwer Academic.

Magnani, L. (2009). Abductive Cognition: The Epistemological and Eco-Cognitive Dimensions of Hypothetical Reasoning. Heidelberg: Springer-Verlag.

McCune, L. (1995). A normative study of representational play at the transition to language. Developmental Psychology 31(2), 198-206.

Neisser, U. (2004). Memory development: New questions and old. Developmental Review 24, 154-158.

Oakes, L., Ross-Sheehy, S. \& Luck, S. (2007). The development of visual short-term memory in infancy. In Short- and Long-Term Memory in Infancy and Early Childhood, L. Oakes \& P. Bauer (Eds.), 75-102. Oxford: Oxford University Press.

Paavola, S. (2005). Peircean abduction: Instinct or inference? Semiotica 153(1/4), 131-154. 
Public Journal of Semiotics 7 (2)

Peirce, C.S. (i. 1866 - 1913). The Collected Papers of Charles Sanders Peirce, Vols. I - VI eds. Charles Hartshorne and Paul Weiss (Cambridge, Massachusetts: Harvard University Press 1931 - 1935), Vols. VII - VIII ed. Arthur Burks (Same publisher, 1958).

Peirce, C.S. (i. 1866 - 1913). The Essential Peirce: Selected Philosophical Writings. Vol. 1, N. Houser \& C. Kloesel (Eds.); Vol. 2, Peirce Edition Project, (eds.). Bloomington: University of Indiana Press, 1992-1998.

Peirce, C.S. (i. 1866 - 1913). Unpublished manuscripts are dated according to the Annotated Catalogue of the Papers of Charles S. Peirce, ed. Richard Robin (Amherst: University of Massachusetts Press, 1967), and cited according to the convention of the Peirce Edition Project, using the numeral " 0 " as a place holder.

Peirce, C.S. (i. 1867-1871). Writings of Charles S. Peirce: A Chronological Edition, Vol. 2. E. Moore, et al. (Eds.). Bloomington: Indiana University Press, 1984.

Peirce, C.S. (i. 1872-1878). Writings of Charles S. Peirce: A Chronological Edition, Vol. 3. C. Kloesel, et al. (Eds.). Bloomington: Indiana University Press, 1986.

Perner, J. \& Ruffman, T. (1995). Episodic memory and autonoetic consciousness: Developmental evidence and a theory of childhood amnesia. Journal of Experimental Child Psychology 59, 516-548.

Piaget, J. (1945/1962). Play, Dreams, and Imitation in Childhoood. Trans. C. Gattegno \& F.M. Hodgson. New York: W.W. Norton.

Piaget, J. (1961/1969). The Mechanisms of Perception. G.N. Seagrim (Trans.). New York: Basic Books.

Pillemer, D.B. (1992). Remembering personal circumstances: A functional analysis. In U. Neisser \& E. Winograd (Eds.), Affect and Accuracy in Recall: Studies of "Flashbulb" Memories, (236-264). New York: Cambridge University Press.

Pillemer, D.B., \&White, S.H. (1989). Childhood events recalled by children and adults. Advances in Child Development and Behavior 21, 297-340.

Sachs, J. (1983). Talking about the there and then: The emergence of displaced reference in parent-child discourse, in K.E. Nelson, Children's Language, Vol. 4 (1-28). London: Psychology Press.

Saylor, M. M. (2004). Twelve- and 16-month-old infants recognize properties of mentioned absent things. Developmental Science 7(5), 599-611.

Tanz, C. (1980/2009). Studies in the Acquisition of Deictic Terms. London: Cambridge University Press.

Taylor, M. (1998). Imaginary Companions and the Children Who Create Them. Oxford: Oxford University Press.

Tomasello, M. \& Brandt, S. (2009). Flexibility in the semantics and syntax of children's early verb use. Monographs of the Society for Research in Child Development 74(2), 113126.

Tulving, E. (2002). Episodic memory: From mind to brain. Annual Review of Psychology 53, $1-25$.

Tulving, E. (2005). Episodic memory and autonoesis: Uniquely human? In H.S. Terrace \& J. Metcalfe (Eds.), The Missing Link in Cognition: Origins of Self-Reflective Consciousness (3-56). Oxford: Oxford University Press.

Vygotsky, L.S. (1934/1962). Thought and Language. Trans. E. Hanfman \& G. Vakar. Cambridge, MA: MIT Press. 
West, D.E. (1986). The Acquistion of Person and Space Deictics: A Comparison Between Blind and Sighted Children. Unpublished Doctoral Dissertation, Cornell University.

West, D.E. (2011a). Indexical reference to absent objects: Extensions of the Peircean notion of index. In K. Haworth, J. Hogue, and L. Sbrocchi, (eds.) Semiotics 2010, 153-165. Toronto: Legas Press.

West, D.E. (2011b). Deixis as a symbolic phenomenon. Linguistik Online 50(6), 89-100.

West, D.E. (2013). Deictic Imaginings: Semiosis at Work and at Play. Heidelberg: SpringerVerlag.

West, D.E. (2014). Perspective switching as event affordance: The ontogeny of abductive reasoning. Cognitive Semiotics 7(2), 149-175.

West, D.E. (2016a). "Recommendations as Imperative Propositions in the Operation of Abductive Reasoning: Peirce and Beyond." IfCoLog Journal of Logics and their Applications 3 (1), 123-150.

West, D.E. (2016b). Indexical scaffolds to habit formation. In D. West and M. Anderson, (eds.), Consensus on Peirce's Concept of Habit: Before and Beyond Consciousness, 215-240. Heidelberg: Springer-Verlag.

West, D. (2016c). Reflections on complexions of habit. In D. West and M. Anderson (Eds.), Consensus on Peirce's Concept of Habit. Before and Beyond Consciousness, 421-432. Heidelberg: Springer-Verlag.

West, D. (2016d). Toward the final interpretant in children's pretense scenarios. In J. Pelkey (Ed.), Semiotics 2015, 101-109. Charlottesville, VA: Philosophy Documentation Center Press.

West, D. (in press). The abductive character of Peirce's virtual habit. In J. Pelkey and S. Walsh-Matthews (Eds.), Semiotics 2016. Charlottesville, VA: Philosophy Documentation Center Press.

Author address

westsimon@twcny.rr.com or donna.west@cortland.edu

State University of New York at Cortland

Department of Modern Languages

P.O. Box 2000

Cortland, NY 13045 USA

About the author

Donna E. West is Professor of Modern Languages and Linguistics at the State University of New York at Cortland (USA). For more than twenty-five years she has been presenting and publishing internationally in semiotic studies using Peirce's sign system, and comparing it to semiotic properties in the works of Karl Bühler, Lev Vygotsky, and Jean Piaget. She is the first investigator to apply a developmental psycholinguistic perspective (supplying fresh data) to Peirce's ten-fold division of signs; as such, her work offers empirical answers to phenomenological questions. Her 2013 book, Deictic Imaginings: Semiosis at Work and at Play investigates the role of Index in the acquisition of demonstratives and personal pronouns. The impetus for the 2016 anthology Consensus on Peirce's Concept of Habit: Before and Beyond Consciousness (which she edited) derives from her fascination with how Peirce's habit relies chiefly upon index's role in establishing event profiles. 